\title{
O PROCESSO DE BOLONHA, A AVALIAÇÃO DA EDUCAÇÃO SUPERIOR E ALGUMAS CONSIDERAÇÕES SOBRE A UNIVERSIDADE NOVA
}

\author{
Licínio C. LiMA* \\ Mário Luiz Neves de Azevedo** \\ Afrânio Mendes CATANI***
}

Recebido em: 25 de novembro 2007

Avaliado em: 10 de fevereiro de 2008

* Professor no Instituto de Educação e Psicologia da Universidade do Minho, Portugal.
** Professor no Centro de Ciências Humanas, Letras e Artes da Universidade Estadual de Maringá.
*** Professor na Faculdade de Educação da Universidade de São Paulo e no PROLAM-USP. Pesquisador
do CNPq.

Resumo: O presente artigo analisa o que se convencionou chamar de Processo de Bolonha, isto é, a produção de uma "política pública de um meta-Estado para um meta-campo universitário", constituindo-se em uma política educacional supranacional, comum aos estados-membros da União Européia, com vista à construção de um "espaço europeu de educação superior". O processo político e de reformas institucionais, realizado por cada governo nacional, conduzirá ao estabelecimento efetivo do novo sistema europeu de educação superior até 2010, incluindo atualmente 45 países - todos os da UE e outros 18 países europeus não pertencentes a ela. Nesse sentido, por se tratar de um vastíssimo número de "subsistemas nacionais" e de instituições educativas, atribui-se um grande protagonismo às questões relativas à "garantia de qualidade". Analisam-se, igualmente, as recentes transformações na educação superior no Brasil, em que o projeto da chamada "Universidade Nova" e o Programa de Apoio a Planos de Reestruturação e Expansão das Universidades Federais (REUNI) constituem-se nas manifestações mais claras do reordenamento desse nível de ensino (seguindo os parâmetros de Bolonha), que já experimentara grandes transformações nos governos de Fernando Henrique Cardoso (1995-2002) e teve prosseguimento nos governos de Luiz Inácio Lula da Silva (2003-2006; 2007), embora com distintos matizes.

Palavras-chave: Processo de Bolonha. Avaliação da educação superior. Universidade Nova e REUNI.

\section{BOLOGNA PROCESS, HIGHER EDUCATION AND \\ A FEW CONSIDERATIONS ABOUT THE NEW UNIVERSITY}

\begin{abstract}
This article analyzes what is conventionally known as the Bologna Process, or the making of a "public policy of a meta-State for a University meta-field" that corresponds to a supranational educational policy for all the European Union membership States, with the goal of building a "European higher education space." The political process and the institutional reforms of each national government intends to establish the new European higher education system until 2010, with 45 countries - the number reflects current developments, including the EU membership States and 18 non-EU countries. Given the high quantity and the myriads of "national subsystems" and educational institutions involved, "quality assurance" becomes a major task in this process. We analyze, in the same way, the recent higher education changes in Brazil, where the so-called "New University" project and the Program of Support for the Restructuring and Expansion of Brazilian Federal Universities (REUNI, in Portuguese) are the clearest expressions of the reshaping of the higher education system (in accordance with the Bologna standards) after the dramatic changes made by Fernando Henrique Cardoso's government (1995-2002) and continued by Luiz Inácio Lula da Silva's government (2003-2006; 2007), despite some differences between both administrations.
\end{abstract}

Key words: Bolonha's Process. Higher education evaluation. Universidade Nova. REUNI. 


\section{A criação de um sistema europeu de educação superior}

Construção sócio-histórica primordialmente européia, a instituição universitária configura-se como uma instância cultural multissecular, aparentemente objeto de generalização em termos organizacionais, evidenciando importantes elementos invariantes do ponto de vista morfológico e processual. No entanto, mesmo apenas à escala européia, e não obstante a história partilhada e a longa duração do seu processo de institucionalização, as universidades fixaram e mantiveram inúmeros elementos próprios, de natureza nacional ou regional, face a especificidades de ordem política, religiosa, cultural, econômica, das quais resultaram distintos "modelos" (por exemplo os modelos napoleônico e humboltdiano), diferentes relações com o Estado e a administração pública, estatutos jurídicos variados, projetos educativos e culturais, e ainda formas de organização dos estudos, consideravelmente plurais.

A divergência de modelos institucionais, de configurações e de regras organizacionais da educação superior na Europa é um fato histórico reconhecido que não foi, até recentemente, representado como um problema a resolver. Tal diversidade resultava de um longo processo de construção, da história e da cultura de cada país, da influência de regimes políticos, de reformas ou revoluções, da ação do Estado ou das Igrejas, sendo, tal como noutros continentes, freqüentemente representada como uma heterogeneidade enriquecedora; um produto histórico-cultural e o resultado, também, da capacidade de auto-governo e do exercício da autonomia das universidades.

Assim, mesmo considerando a sua matriz histórica comum, a circulação das idéias e da cultura universitária, a vários títulos precursora das atuais práticas intensivas de internacionalização, as universidades européias foram edificadas, na maioria dos casos, por referência a comunidades, a cidades, a regiões e a nações, a culturas e a línguas distintas, representando, afinal, apenas mais um dos elementos que caracterizam a grande diversidade cultural de uma Europa que, de resto, se viu por inúmeras vezes dividida por conflitos e destruições. Já em termos de regulação, as universidades públicas modernas viriam a tornar-se dependentes, e simultaneamente um dos pilares simbólico-culturais, de cada Estado-nação, designadamente através de políticas públicas, de legislação prescritiva e de financiamento estatal.

Em termos jurídico-formais aquela situação manteve-se genericamente inalterada, mesmo após a segunda guerra mundial e a assinatura do Tratado de Roma (1957), com a criação da então designada Comunidade Econômica Européia (CEE), passando pelo Tratado de Maastricht (1992), com a emergência 
da União Européia, atualmente constituída por vinte e sete estados-membros. Porém, a partir sobretudo da década de 1980 emergem novos modos de governo e regulação da educação superior, especialmente induzidos pelas reformas do Estado-providência em certos países, fazendo sobressair concepções liberalizantes e um modelo institucional distinto daquele dos países nórdicos e dos países da Europa do Sul, a que se poderia chamar, por conveniência, de tipo anglo-americano.

Se a um primeiro tempo se assiste à introdução de uma ainda maior diversidade no campo universitário europeu, a referida divergência cedo viria a ser objeto de um progressivo esbatimento, devido a múltiplos fatores, entre os quais: à adoção de princípios políticos semelhantes no que concerne às reformas do Estado e da administração pública, aos efeitos da globalização em termos econômicos e sociais, mas também em termos culturais e de políticas educacionais, à ação de importantes instâncias transnacionais, como a UNESCO, a OCDE, o BM etc. A própria União Européia (UE), embora não comprometida, do ponto de vista formal, com uma política educativa comum, tem-se revelado um ator cada vez mais relevante, podendo com propriedade falar-se de um "fenômeno de deslocação do processo de formação das políticas para a educação em direção ao nível supranacional" (ANTUNES, 2006a, p. 65; DIAS SOBRINHO, 2005, p. 169-195).

Adotando programas de cooperação e de financiamento, produzindo relatórios, livros brancos e outros textos de natureza político-normativa, decidindo freqüentemente através da nova metodologia da "adesão voluntária" dos governos nacionais a políticas comuns ou, noutros casos, podendo vir a admitir processos de opting-out (ficar-de-fora, ainda que transitoriamente), estabelecendo metas e objetivos a atingir, avaliações intermediárias e recomendações vigorosas, a UE vem-se revelando um autêntico locus supranacional de definição de políticas educacionais de caráter transnacional, com particular destaque, atualmente, para a educação superior. Conforme já foi observado, trata-se de algo sem precedentes: da produção de uma "política pública de um meta-Estado para um meta-campo universitário" (AZEVEDO, 2006, p. 173), ou seja, de uma política educacional supranacional, comum aos estados-membros da União, com vista à construção de um "espaço europeu de educação superior". E é aqui, face ao novo desígnio de criação de um sistema europeu de educação superior, sem dúvida impulsionado e regulado pela União, mas com um alcance que já ultrapassa, em muito, as suas fronteiras políticas atuais, que o modelo institucional de tipo anglo-americano emerge em toda a sua expressão, seja em termos estruturais, seja em termos de regulação e de competitividade, e, 
até, de hegemonia lingüística, com o inglês e a cultura anglo-americana como referências centrais.

O processo político e de reformas institucionais, internamente processadas por cada governo nacional ou respectivas entidades descentralizadas, que deverá conduzir ao estabelecimento efetivo do novo sistema europeu de educação superior, até 2010, incluindo atualmente quarenta e cinco países (isto é, todos os da UE e, ainda, dezoito países europeus não pertencentes à UE), foi designado por Processo de Bolonha.

Em 1998, em Paris, os ministros da educação da Alemanha, França, Itália e Reino Unido assinaram uma declaração conjunta onde perspectivam já a construção de um “espaço europeu de educação superior” (DECLARAÇÃO DA SORBONNE, 1998). No ano seguinte, os ministros de vinte e nove estados europeus, incluindo Portugal, subscreveram a chamada Declaração de Bolonha (1999), onde assumem como objetivos o estabelecimento, até 2010, de um espaço europeu de educação superior coerente, compatível, competitivo e atrativo para estudantes europeus e de países terceiros.

A construção do referido sistema europeu de educação superior é considerada "a chave para promover a mobilidade e a empregabilidade dos cidadãos" e para a "obtenção de maior compatibilidade e de maior comparabilidade". Embora se recuse a idéia de simples homogeneização ou padronização, eventualmente menos aceitável face à grande diversidade da educação superior dos países aderentes, insiste-se na harmonização e na necessidade da coordenação de políticas, na promoção da dimensão européia dos currículos, na cooperação internacional, na mobilidade e no intercâmbio, bem como na cooperação no "setor da avaliação da qualidade, tendo em vista vir a desenvolver critérios e metodologias que sejam passíveis de comparação (DECLARAÇÃO DE BOLONHA, 1999).

Os princípios destacados e as respectivas linhas de ação - sistema de graus legível e comparável, sistema de ciclos de estudos, sistema de créditos comum, mobilidade, cooperação na avaliação, dimensão européia - revelam-se absolutamente indispensáveis não apenas face à idéia de convergência e de sistema europeu, mas também face aos mais centrais objetivos políticos: "promover o sistema europeu de educação superior em todo o mundo", tornando-o fortemente competitivo face, sobretudo, aos Estados Unidos da América, designadamente pela atração de estudantes de outros continentes, designadamente o asiático. $\mathrm{O}$ texto da Declaração de Bolonha não se revela nada enigmático quanto à opção pelo princípio da competitividade em termos não só de emulação, de eficiência e de financiamento, mas também de lógica mercantil, assumindo com clareza 
a idéia da centralidade da Europa no fornecimento de serviços educativos, de resto de matiz assumidamente etnocêntrico:

Em especial, deve-se ter em conta o objetivo de elevar a competitividade internacional do sistema europeu de educação superior. A vitalidade e a eficiência de qualquer civilização podem medir-se pela atração que a sua cultura exerce sobre os outros países. Precisamos assegurar que o sistema europeu de educação superior consiga adquirir um grau de atração mundial semelhante ao das nossas extraordinárias tradição cultural e científica.

A argumentação produzida revela-se compatível com a chamada Estratégia de Lisboa, aprovada em 2000 pela UE sob a presidência portuguesa, a qual assume a criação do "espaço econômico mais dinâmico e competitivo do mundo", baseado no conhecimento e capaz de garantir um crescimento econômico sustentável, com mais e melhores empregos e com maior coesão social. Uma criação que, até ao momento, se vem revelando bastante mais difícil de realizar do que aquilo que inicialmente se havia previsto.

O Processo de Bolonha, contudo, tem-se revelado um processo dinâmico, fortemente liderado e monitorado periodicamente, tendo sido assumido em certos casos como um "musculadíssimo e duríssimo programa de formatação dos cursos e graus" (ANTUNES, 2006a, p. 69). O Comunidado de Praga (2001) virá acrescentar mais três linhas de ação relativas à promoção da atratibilidade do espaço europeu da educação superior, ao maior envolvimento dos estudantes na gestão das instituições e à promoção da educação/aprendizagem ao longo da vida. Essa última tem-se tornado uma referência permanente, apontando paradigmaticamente para um referencial pedagógico centrado no estudante e no seu trabalho, bem como na abertura a "novos públicos" para a educação superior, em muitos países europeus a atravessar uma crise motivada por relativamente estabilizadas taxas de cobertura que, em conjunto com o decréscimo da natalidade, significam vagas ociosas e práticas competitivas sem precedentes pela atração de alunos. Porém, a aprendizagem ao longo da vida apresenta-se quase sempre como um discurso política e conceitualmente enigmático, parecendo tender a conferir protagonismo às vertentes mais competitivas e individualistas, à adaptação e à empregabilidade, ao treinamento e à qualificação para o crescimento económico, naquilo que já foi designado como "a mão direita da educação ao longo da vida." (LIMA, 2007).

Entretanto, em 2003, o Comunicado de Berlim dava conta da decisão de colocar em funcionamento pleno o sistema europeu de créditos (ECTS - European 
Credit Transfer and Accumulation System), obedecendo a regras de contabilização precisas, e também passar a fornecer aos estudantes o Suplemento ao Diploma, um documento escrito numa língua estrangeira de grande circulação onde se descreve o programa de estudos e, entre outros elementos, se certificam as chamadas "competências transversais" de cada aluno. Finalmente, o comunicado refere-se ainda a decisão de reforçar as sinergias entre o "espaço europeu de educação superior" e o "espaço europeu de investigação". Em 2005, o Comunicado de Bergen destacou os elementos relativos à "garantia da qualidade" da educação superior européia, tendo os ministros decidido adotar as propostas de Associação Européia para a Garantia da Qualidade da Educação Superior (ENQA, 2005) relativas aos "standards" e às "orientações" a que deverão passar a obedecer as avaliações promovidas pelas agências nacionais e internacionais, as quais, de resto, virão a integrar um registro europeu de agências de garantia da qualidade, o qual exigirá, por sua vez, a meta-avaliação e a meta-acreditação das próprias agências. Finalmente, o Comunicado de Londres (2007) afirmava a necessidade de "responder eficazmente aos desafios da globalização" e de construir um espaço europeu de educação superior baseado em "autonomia institucional, liberdade acadêmica, igualdade de oportunidades e princípios democráticos que facilitarão a mobilidade, aumentarão a empregabilidade e fortalecerão a atratividade e competitividade da Europa."

É visível, com efeito, uma reforma da educação superior à escala européia, sem precedentes, em que se destaca, em primeiro lugar, uma grande perda de protagonismo dos estados nacionais, a tal ponto que talvez se possa falar de uma espécie de "desnacionalização" da educação superior ou, de outro ponto de vista, de uma decisiva e definitiva "europeização" das universidades e outras escolas superiores, optando por políticas de liberalização e pela necessária harmonização para a emulação e a competitividade, vencendo barreiras e fronteiras tradicionais. A este propósito observou Fátima Antunes: "tipicamente, a desregulação liquefaz as fronteiras geográfico-políticas e territoriais para maximizar o valor de troca e, portanto, potenciar o poder inscrito na capacidade aquisitiva, capital econômico e cultural e/ou no estatuto individual e coletivo" (ANTUNES, 2006a, p. 69). Assiste-se, assim, a um complexo processo de redução da autonomia relativa dos estados nacionais em matéria de educação superior; a uma direção supranacional de políticas, agora relativamente descontextualizadas; a uma deslocalização das arenas de debate e dos processos de discussão democrática de tipo tradicional; à não participação ou a uma participação fluida e difusa dos atores educativos diretamente envolvidos, em favor da intervenção de stakeholders altamente organizados e institucionali- 
zados; à emergência de novas tecnoestruturas e especialistas (gestores, grupos de missão, peritos e avaliadores profissionais etc.); a uma adaptação célere e por vezes sem discussão das legislações nacionais, assim sobre-determinados externamente à escala européia e freqüentemente subtraídas do processo de deliberação democrática; à produção de estudos internacionais, de avaliações externas e exames de política, acompanhados de processos diversos de pilotagem e monitorização transnacional e pela imposição de mecanismos externos de "prestação de contas"; à definição externa e a priori de "problemas" a enfrentar e de "soluções" a adotar, aparentemente universais ou, pelo menos, não contingentes e situados, apresentados como imperativos racionais ou como exemplos incontornáveis de "boas práticas" (ver, entre outros trabalhos, ANTUNES, 2006b; MAGALHÃES, 2004; SEIXAS, 2003).

Observa-se, atualmente, um processo de dupla centralização política, seja em termos europeus, transnacionais, face a cada um dos estados membros ou países aderentes, seja também em termos internos, ou nacionais, com os governos a chamar a si a decisão política e a estratégia adaptativa face às condicionantes globais. O Processo de Bolonha ficará para a história como um processo político fortemente governamentalizado em termos nacionais, no contexto de certos países, e externamente sobredeterminado por agendas transnacionais. Voluntariamente, nenhum governo nacional parece disposto a ficar de fora do processo, preferindo aderir, mesmo quando as conseqüências da criação de um sistema europeu altamente competitivo e internacionalmente avaliado, curso a curso, instituição a instituição, país a país, venham provavelmente a produzir resultados dramáticos para alguns dos participantes como, aliás, exige uma lógica de emulação de tipo mercantil, com a correspondente criação de mercados externos e internos. Em qualquer dos casos, as universidades e outras escolas superiores não só não lideram o processo de integração no sistema europeu, como nem sequer foram auscultadas acerca da sua vontade em participar. Daqui decorrem processos genericamente caracterizados pela pouca consulta, por insuficiente debate público e por pouca ou nula participação no processo de tomada de decisões.

Os diferentes modos de regulação centralizada revelam-se, paradoxalmente, indispensáveis à orientação econômica dominante e à adoção de mecanismos de desregulação e liberalização típicos do funcionamento dos mercados competitivos. O Processo de Bolonha "apela à urgência de enfrentar as exigências da competitividade internacional do sistema do ensino superior" e a Comissão Européia não faz segredo da assumida "rivalidade euro-americana" no que à educação superior e à "economia do conhecimento" se refere (PORTUGAL, 2004). 
O Processo de Bolonha, com vista à criação de um espaço europeu de educação superior altamente integrado e competitivo, exige um movimento em direção à convergência, para que se possa falar de um sistema, sujeito às mesmas orientações e regras, e para que a competição interna possa funcionar segundo critérios comuns e comparáveis. Um mercado competitivo de educação superior requer um mínimo de regulação relativa ao estabelecimento das grandes regras do jogo competitivo e da inclusão das instâncias competidoras, da estrutura comum dos serviços a prestar, dos critérios de avaliação da sua qualidade e da informação a prestar aos consumidores.

Por tudo isso, os elementos de convergência revelam-se assentes em normas injuntivas detalhadas e padronizadas. Trata-se de uma convergência normativa, estrutural e morfológica capaz de integrar os fornecedores de serviços educativos num sistema comum, impondo-lhes pré-requisitos mas, simultaneamente, num sistema competitivo e, por essa razão, altamente diferenciado. Estaremos perante uma convergência normativa indispensável à integração das instituições, mas logo orientada para a divergência competitiva e diferenciadora, baseada na rivalidade interinstitucional, dentro e fora de cada país, na busca incessante por vantagens competitivas. Convergir para divergir, ou integrar para diferenciar, seriam os lemas mais adequados, no sentido de estabelecer uma dinâmica onde a rivalidade se torna imediatamente visível e comparável, traduzida na capacidade de atração de mais alunos e de certos tipos de alunos, designadamente estrangeiros, de captação de novos recursos financeiros, de projetos de prestação de serviços ao mercado, de conquista de novos mercados e públicos, de subida de posições nos rankings nacionais e europeus, e tudo isto independentemente das condições contextuais e de partida de cada instituição de educação superior.

É por todas essas razões que a educação superior enquanto bem público, assumindo uma dimensão social e de política pública democrática, surge consideravelmente negligenciada no Processo de Bolonha. As associações representativas dos estudantes europeus têm-se afirmado como um dos setores mais críticos, observando que as condições dos estudantes raramente têm melhorado, que os entraves financeiros à mobilidade persistem, que a participação estudantil nos processos de avaliação continua muito frágil, que o acesso ao segundo ciclo (mestrado) e ao terceiro ciclo (doutorado) se encontra bastante dificultado em certos países, até pelo pagamento de taxas elevadíssimas que, segundo a OCDE, se devem progressivamente aproximar dos custos reais por aluno. No último relatório produzido, intitulado Bologna with Student Eyes (ESIB, 2007), os estudantes criticam as derivas economicistas e as lógicas 
do marketing à escala global na promoção comercial da educação superior, a qual parece surgir como muito atrativa mas, especialmente, para apenas uma pequena parte dos estudantes de países terceiros com capacidade para pagar os seus estudos na Europa (Ibid, p. 8).

Entretanto, mesmo a agenda pedagógica do Processo de Bolonha, sem dúvida a sua dimensão mais elogiada carece, em muitos países, de investimento e de condições capazes de induzir a profundas alterações a serem processadas. No caso português, pelo contrário, "a diminuição em termos reais do financiamento do ensino superior a que se tem assistido [...] não poderá deixar de constituir fator de preocupação, em especial porque as reformas de fundo a implementar, que deverão passar por uma reorganização pedagógica profunda, exigem um esforço e investimento inicial muito significativo" (SIMÃO; SANTOS; COSTA, 2005, p. 45). Com efeito, no ano letivo 2006-2007 foram operados cortes governamentais no orçamento da educação superior da ordem dos $15 \%$, por efeito conjugado de diferentes medidas. Diversas medidas de "racionalização" e de downsizing têm sido levadas a cabo, através de lógicas gerencialistas que tendem a tornar ainda mais precários os vínculos laborais dos docentes, na sua grande maioria sem nomeação definitiva.

A redução da duração dos cursos de primeiro ciclo (graduação), em certos casos na ordem de dois anos, parece constituir-se, conforme se temia, como uma boa oportunidade para adotar lógicas de redução de encargos por parte do Estado, e não para reforçar as condições de trabalho nas escolas, designadamente em termos pedagógicos. Se assim se mantiver, mesmo a pedagogia universitária proposta pelo Processo de Bolonha correrá o risco de ser uma mudança superficial ou cosmética, limitada à introdução de um novo léxico reformador (unidade curricular, resultados da aprendizagem, horas de contato etc.) sem grande substância e incapaz de promover mudanças na organização do trabalho docente e discente, na adoção de esquemas de apoio tutorial aos estudantes, na dimensão das turmas, na alteração dos processos de avaliação e na atenção à formação cultural, ético-política e cívica dos estudantes.

\section{Avaliação da qualidade: estandardização e meta-regulação}

O Processo de Bolonha, tendo em vista a criação de um espaço europeu de educação superior capaz de integrar e, simultaneamente, de diferenciar um vastíssimo número de "subsistemas nacionais" e de instituições educativas, tem atribuído grande protagonismo às questões relativas à "garantia da qualidade." 
A um sistema europeu de educação superior deverá corresponder uma agência européia de avaliação ou, no mínimo, uma entidade ou associação européia das agências nacionais, capaz de as regular e, eventualmente, de as acreditar e avaliar, de maneira a constituir um registro europeu de agências de "garantia da qualidade", devidamente acreditadas (ENQA, 2005). A meta-acreditação e a meta-avaliação das agências de acreditação e avaliação, já previstas pela ENQA através de processos externos cíclicos (p. 36), pretendem não apenas garantir a confiança na ação das agências, mas também regular a sua emergência e o seu funcionamento, temendo-se a criação de agências exclusivamente orientadas para a obtenção de lucros, de tipo empresarial, a oferecer os seus serviços numa lógica de mercado competitivo.

Quanto à "garantia da qualidade" da educação superior, ela tem estado na base do lançamento de múltiplos sistemas de avaliação, conselhos e agências nacionais (dos cursos ou programas, da pesquisa, das instituições ou mesmo dos sistemas nacionais ou regionais). A regulação transnacional de tais iniciativas, até recentemente dependentes de legislação nacional corresponde, agora, a uma exigência do Processo de Bolonha e, nesse sentido, a ENQA produziu já standards e "orientações" com vista à integração dos processos de avaliação em nível europeu.

Embora seja afirmado que se recusam orientações estreitas, prescritivas e muito formalizadas dos standards, ou "padrões", antes se preferindo adotar "princípios genéricos" e standards genéricos, a verdade é que também é afirmado que os standards propostos deverão ser aplicados a todas as instituições de educação superior e a todas as agências de avaliação, "independentemente da sua estrutura, função, tamanho e sistema nacional em que se encontrem integrados" (p. 11), sendo de resto bastante sistemáticos na sua inventarização e definição e, ainda, nos respectivos procedimentos previstos.

Como se compreende, a avaliação externa, estandardizada, pelo menos relativamente a quesitos e matérias centrais, revela-se incontornável em face dos objetivos, simultâneos, de integração e de diferenciação; ou, em outros termos, de convergência sistêmica e estrutural orientada politicamente para a divergência competitiva e mercantil. Neste sentido se têm manifestado diversos observadores, esclarecendo como a "garantia da qualidade" exige mensuração, comparação e competitividade, através de "carteiras de indicadores internacionalmente comparáveis, aceites e partilhados por todas as instituições" (SIMÃO; SANTOS; COSTA, 2005, p. 185), mesmo quando o critério da aceitação e da partilha por "todas as instituições" dificilmente possa ser atingido. Esclarecem os autores: "A sociedade do conhecimento exige qualidade, em termos men- 
suráveis, e a realização dos objetivos em tempo oportuno. Mensurabilidade e temporalidade são as suas características determinantes. A produtividade e a competitividade não podem, pois, ser eliminadas por um humanismo também ele imprescindível mas, por isso mesmo, integrante e não antagônico do economicismo e das boas práticas de gestão.” (p. 177).

Remete-se, portanto, para a criação de um "sistema europeu de garantia de qualidade", a que se deverão subordinar as futuras agências de avaliação e acreditação nacionais (para o caso de Portugal veja-se o Decreto-Lei n ${ }^{\circ} 74 / 2006$, de 24 de Março, Portugal, 2006). Tais agências poderão intervir em termos de avaliação, numa lógica de "melhoria da qualidade", e também em termos de acreditação, nesse caso mais numa "lógica de controle". Seja por processos de acreditação ex ante, seja por intermédio de processos de acreditação ex post.

Em qualquer dos casos, e ainda que se possam encontrar algumas defesas, algo sincréticas, de uma espécie de paradigma de avaliação do tipo humanistaeconomicista, a orientação dominante revela-se de tipo positivista e competitivo, como reconhece a própria ENQA no seu relatório relativo a Portugal: "A Educação superior, num contexto de globalização, tem começado a evidenciar características de um mercado" (ENQA, 2006, p. 9). Ora é em contexto de mercado que o atual paradigma de universidade vem sendo substituído "por um paradigma empresarial a que devem estar sujeitos tanto as universidades públicas, como as privadas, e o mercado educacional em que estas intervêm deve ser desenhado globalmente para poder maximizar a sua rentabilidade", conforme conclui Boaventura de Sousa Santos (2005, p. 149). E é precisamente face ao paradigma empresarial que "a liberdade acadêmica é vista como um obstáculo à empresarialização da universidade e à responsabilização da universidade ante as empresas que pretendem os seus serviços" (p. 150). É também neste quadro de referência que se podem cabalmente compreender as propostas de tipo tecnocrático e gerencialista no sentido de transformar as universidades em fundações de direito privado, dotadas de estruturas tipicamente empresariais, de que é exemplo recente, para o caso português, o relatório sobre o ensino superior elaborado pela OCDE (2006), de resto seguido pelo governo português na sua proposta de lei apresentada ao parlamento, concernente a um novo Regime Jurídico das Instituições de Ensino Superior (PORTUGAL, 2007a). Aqui se propõe, entre outros aspectos, a substituição dos atuais órgãos de governo por um "conselho geral" a quem caberá a designação do reitor, na seqüência das críticas apresentadas pela OCDE e por outras instituições internacionais aos órgãos colegiais e aos elementos de democracia participativa, agora representados como fatores de ingovernabilidade e de ineficiência das escolas. 
Trata-se da defesa de um modelo institucional de feição gerencialista para as universidades, inspirado na atividade empresarial, procurando transferir o governo das instituições para uma tecno-estrutura gestionária e para o mercado. A autonomia institucional e a liberdade acadêmica tendem, agora, a ser reconceituadas como técnicas de gestão, subordinadas a um novo paradigma de educação a que, há uma década atrás, um dos autores deste texto chamou paradigma da "educação contábil" (LIMA, 1997), isto é, a valorização da educação "que é orientada segundo objetivos precisos e que dessa forma se torna contável através da ação de instâncias de contadoria e dos respectivos agentes e processos contadores" (p. 55). Por essa razão se centra no cálculo e na medição de resultados, desvaloriza os processos e os resultados mais difíceis de mensurar e comparar, favorece a padronização, de tal forma que "as escolas, os ensinos e as aprendizagens são abordados como elementos validados, fiáveis, fidedignos, procurando esbater as imperfeições e subjetividades." (p. 55-56). Daqui resulta uma concepção de avaliação de tipo tecnocrático e gerencial, predominantemente externa e quantitativa, estandardizada, centrada na comparação entre produtos e, em geral, recusando processos de auto-avaliação conduzidos livremente por critérios próprios, fruto da autonomia acadêmica e da capacidade de auto-governo. Dispositivos de avaliação formativa, dialógica ou participativa são, em tal contexto, considerados inaceitáveis, uma vez considerados subjetivos, internos, situados, isto é, incapazes de garantir a "absoluta exterioridade" dos agentes avaliadores, conforme exige, por exemplo, o projeto do governo português para a criação da Agência de Avaliação e Acreditação para a Garantia da Qualidade do Ensino Superior (PORTUGAL, 2007b, p. 3). Exterioridade e heteroavaliação surgem, naquele documento, como garantes da independência, do rigor e da objetividade do processo de avaliação, sem por uma vez se questionar a possível deriva positivista de tal concepção avaliativa.

Parece, na verdade, que a maior distância geográfica, cultural, lingüística etc., permitirá a emissão de juízos de valor mais "objetivos", incontaminados pelo contexto e pelas relações sociais. No mesmo sentido, os objetos a avaliar são representados como "dados" dados, ou captáveis em toda a sua "pureza", ou "em estado bruto", não sendo o resultado de um processo de construção pelos avaliadores, "modelizados" em função de um "sistema de referências" que é sempre, por definição, político e convencional (FIGARI; TOURMEN, 2006). O processo de naturalização e de despolitização das relações complexas, e mesmo dos confrontos, entre "referidos" e "referentes", inerentes a todo o processo avaliativo, pode ser visto como um indicador do processo mais geral de 
"administrativização" da avaliação da educação superior, em boa parte induzido pelas perspectivas da Nova Gestão Política e suas correspondentes exigências de medição e comparação, de benchmarking, de ratings e de rankings, obtidos através de novos instrumentos de avaliação, auditoria, acreditação, fiscalização, típicos da atividade econômica. A sociedade da auditoria, ou da notação , como já tem sido designada assenta, como observa Rosanvallon (2006), numa democracia da desconfiança organizada e dos poderes indiretos de vigilância e fiscalização, em geral importados da esfera econômica, constituindo-se, segundo o autor, como uma "contra-democracia", de resto dependente da ação dos novos profissionais da avaliação e da prestação dos seus serviços especializados. Em qualquer dos casos sempre preferíveis, pela sua "independência" e pretensa neutralidade axiológica, à avaliação por pares, estes presos à esfera acadêmica e à sua cultura, em certos casos mesmo adeptos de processos intersubjetivos de emissão de juízos, negociando os sentidos a atribuir aos "dados", procurando compreender e interpretar a realidade através de processos hermenêuticos, e não simplesmente descrevê-la e mensurá-la de forma objetivista. Para a ENQA (2006), esses processos sofrem de uma independência limitada, resultando, como no caso português da avaliação por pares, numa situação de "amigos a avaliar amigos", isto é, uma situação em que o conhecimento mútuo das pessoas e dos contextos é considerado um obstáculo à avaliação.

Uma epistemologia positivista revela-se, compreensivelmente, mais funcional aos objetivos políticos desta avaliação de feição tecnocrática, assente no dualismo sujeito/objeto de avaliação. Baseada numa espécie de realismo ingênuo, a avaliação positivista e tecnocrática remete para uma ontologia da exterioridade, na qual a realidade é independente da consciência dos atores. Consequentemente, do ponto de vista metodológico acredita-se que o conhecimento objetivo exige procedimentos de inspiração experimental ou, pelo menos, assentes em relações da causa e efeito entre variáveis, tendendo a reduzir a realidade às suas dimensões mensuráveis. E isto mesmo quando, discursivamente, existem alguns apelos à "triangulação" das fontes, à realização de visitas e de entrevistas, ou à análise de documentos, eventualmente com inspiração etnográfica ou, no mínimo, remetendo para dispositivos de tipo "estudo de caso", no entanto já reduzidos a uma dimensão de legitimação dos processos avaliativos, isto é, sem maiores conseqüências em termos epistemológicos. Uma avaliação de tipo administrado e positivista tende a apresentar-se como um exercício técnico mais do que como um processo de produção de conhecimento ou como uma forma de investigação avaliativa. Trata-se de mais uma forma de desvinculação da atividade avaliativa da esfera acadêmica e de pesquisa, 
opondo à cultura acadêmica a cultura empresarial, à comunidade acadêmica e às suas práticas democráticas o gerencialismo e a competitividade.

É possível que as agências de avaliação e seus respectivos quadros de profissionais da qualidade venham a ser alvos das tensões entre os decisores políticos e o mundo acadêmico, descobrindo no futuro, amargamente, a natureza política e reguladora da avaliação da educação superior, bem como o debate epistemológico a que a sua ação não pode deixar de ser submetida, designadamente através do escrutínio acadêmico. Um estudo recente, promovido pela ENQA e baseado num questionário dirigido às agências de avaliação, revela já a importância do referido debate epistemológico, tal como as dificuldades em torno da heterogeneidade dos valores, dos contextos, das línguas e dos conceitos subjacentes à avaliação, entendida como uma construção social (CROZIER; CURVALE; HÉNARD, 2006).

Porém, os referidos problemas de ordem ontológica, epistemológica e metodológica em torno das práticas de avaliação da educação superior relevam, no essencial, da sua definição política. O paradigma dominante de avaliação contábil e gerencial, baseado numa epistemologia positivista, é justificado pelo papel atribuído à avaliação em termos de regulação da educação superior. É exatamente neste terreno que a estandardização, a lógica positivista e de competitividade servem aos propósitos dos novos modos de regulação emergentes, especialmente induzidos pela reforma do Estado. A tradicional regulação estatal das universidades é afastada a partir do momento em que o Estado passa a ser definido como um "parceiro" que contratualiza com as instituições, já não as controlando diretamente, mas antes supervisando-as. A transição do Estadoregulador para um Estado-supervisor, isto é, do modelo de controle estatal para o modelo de supervisão estatal (AMARAL; MAGALHÃES, 2000), exige a criação de instâncias de intermediação entre as universidades e o Estado, capazes de oferecer um primeiro nível de regulação e controle, a partir da avaliação e da "prestação de contas", necessariamente referenciados a indicadores padronizados de performance (SANTIAGO; MAGALHÃES; CARVALHO, 2005, p. 31). É exatamente o papel das agências de avaliação externa e da produção de rankings, já à escala européia, isto é, envolvendo processos de regulação de tipo transnacional, remetendo para o Estado funções de meta-regulação, assim o concebendo como um "regulador das regulações" (BARROSO, 2006, p. 63), através da descentralização de processos, permitindo e valorizando a diversidade de projetos e de procedimentos mas, ao invés, atuando de forma altamente centralizada em face dos distintos resultados de performance atingidos por cada instituição e "revelados" publicamente na seqüência da avaliação externa. 
As "conseqüências da avaliação" por parte do Estado e designadamente em termos de financiamento público e de manutenção das instituições ou dos seus programas, tal como os "efeitos de mercado" resultantes da informação aos consumidores através da publicização dos resultados, com a respectiva indução de rivalidade insterinstitucional, representam hoje, como se viu, requisitos indispensáveis para a construção de um sistema europeu de educação superior fortemente atrativo à escala global e seguindo uma lógica mercantil.

\section{A chamada Universidade Nova no Brasil e o REUNI}

Na história recente das políticas públicas no Brasil nota-se que as reformas, entre outras motivações ${ }^{1}$, são bastante influenciadas pelo fundamento de política externa, isto é, por modelos estrangeiros, relatórios teóricos e por think tanks transnacionais. A reforma universitária de 1968 no Brasil, por exemplo, durante o regime militar, sofreu a influência do modelo departamental da universidade norte-americana. Nos anos 1990, por sua vez, as reformas do Estado e da educação superior tiveram por referencial teórico o liberalismo ortodoxo emulado pelo Banco Mundial. Já no início do século XXI, qualquer movimento de reforma universitária que se pretende implantar no mundo, entre outras inspirações e referenciais, obriga-se a fazer menção ao Processo de Bolonha que, conforme foi apresentado anteriormente, é uma meta-política pública, de um meta-Estado, iniciada em 1999, de construção de um espaço de educação superior na Europa até o ano de 2010, cujo objetivo essencial é o ganho de competitividade do Sistema Europeu de Ensino Superior frente a países e blocos econômicos. Com tal finalidade, esse projeto pan-europeu objetiva harmonizar os sistemas universitários nacionais, de modo a equiparar graus, diplomas, títulos universitários, currículos acadêmicos e adotar programas de formação contínua reconhecíveis por todos os Estados membros da União Européia.

No Brasil não existe, atualmente, uma norma legal de ensino superior consolidada. O que há, após o descarte das normativas que balizaram as políticas educativas e universitárias durante o regime militar, é um conjunto de leis (entre elas a Lei de Diretrizes e Bases da Educação Nacional - LDB), medidas provisórias e resoluções ministeriais e do Conselho Nacional de Educação (CNE) que, pouco a pouco, vem delineando o modelo universitário. Nos anos 1990, a reforma do sistema de educação superior no Brasil ocorreu em paralelo com a Reforma do Estado, priorizando o livre jogo do mercado. Ou seja, durante

1 Ver, a respeito, o capítulo "Fundamentos de Política Externa, Fundamentos de Política Interna, Fundamentos Críticos e Fundamentos Ideológicos” (AZEVEDO; CATANI, 2005). 
os dois mandatos de Fernando Henrique Cardoso (1995-2002) houve um forte processo de mercadorização das relações sociais.

As propostas para a educação superior, emanadas do Governo de Luís Inácio Lula da Silva, em seu primeiro mandato (2003-2006), guardam características inerciais em relação ao período anterior (FHC) mas, em grande medida, são distintas. Em termos pontuais, a reforma universitária do Governo Lula, analisada a partir das políticas públicas em execução e com base nos princípios presentes no Documento II do MEC e na quarta e última versão do Anteprojeto de Lei enviado, em 12 junho de 2006, à Câmara dos Deputados Federais, tornando-se Projeto de Lei 7200/2006, tem as seguintes marcas:

- Definição de um modelo de financiamento universitário;

- Regulação da transnacionalização das IES privadas;

- Política de cotas para estudantes de escolas públicas, negros e índios e criação do Programa Universidade para Todos (PROUNI);

- Criação de um Conselho com Participação da Comunidade, sindicatos, docentes e funcionários nas Universidades Públicas e Privadas;

- Submissão das universidades ao princípio da Responsabilidade Social;

- Regulação das fundações;

- Avaliação e acreditação das IES com vistas a assegurar a qualidade.

Em 2007, iniciado o segundo mandato do Presidente Lula, o MEC, coincidindo com a tramitação do PL 7200/2006, tem emitido sinais abonadores à proposta de implantação da "Universidade Nova". A idéia é mudar o modelo da estrutura acadêmica da educação superior que passaria a se compor por três ciclos: Bacharelado Interdisciplinar $\left(1^{\circ} \mathrm{Ciclo}\right)$; Formação Profissional $\left(2^{\circ}\right.$ Ciclo); Pós-Graduação ( $3^{\circ}$ Ciclo). De acordo com o Documento Preliminar para Consulta Pública da Universidade Federal da Bahia (UFBA), instituição que, além da Universidade de Brasília (UnB), Universidade Federal do Piauí (UFPI) e Universidade Federal do ABC (UFABC), está em vias de implementar tal processo de reforma,

A proposta atualmente denominada de Universidade Nova implica uma transformação radical da arquitetura acadêmica da universidade pública brasileira, visando a superar os desafios e corrigir [uma série de] defeitos. Pretende-se, desse modo, construir um modelo compatível tanto com o Modelo Norte-Americano (de origem flexneriana) quanto com o Modelo Unificado Europeu (processo de Bolonha) sem, no entanto, significar submissão a qualquer um desses regimes 
de educação universitária. A principal alteração proposta na estrutura curricular da universidade é a implantação de um regime de três ciclos de educação superior:

- Primeiro Ciclo: Bacharelado Interdisciplinar (BI), propiciando formação universitária geral, como pré-requisito para progressão aos ciclos seguintes;

- Segundo Ciclo: Formação profissional em licenciaturas ou carreiras específicas;

- Terceiro Ciclo: Formação acadêmica científica, artística e profissional da pós-graduação.

A introdução do regime de ciclos implicará ajuste da estrutura curricular tanto dos cursos de formação profissional quanto da pós-graduação. Além disso, propõe-se a incorporação de novas modalidades de processo seletivo, para o próprio BI e para as opções de prosseguimento da formação universitária posterior (UFBA, 2007, p. 9).

A possibilidade de materialização da "Universidade Nova" surge com a publicação do Decreto no . 6.096, de 24 de abril de 2007, instituindo o Programa de Apoio a Planos de Reestruturação e Expansão das Universidades Federais (REUNI) que tem por objetivo "criar condições para a ampliação do acesso e permanência na educação superior, no nível de graduação, pelo melhor aproveitamento da estrutura física e de recursos humanos existentes nas universidades federais" (BRASIL, 2007, Art. $1^{\circ}$ ). Apesar do enunciado de boas intenções e de não haver menção ao BI, trata-se, em essência, de estabelecer uma política que procura estimular a adesão a um novo modelo de universidade e uma nova relação de trabalho com os professores. Segundo o mencionado Decreto,

O Programa tem como meta global a elevação gradual da taxa de conclusão média dos cursos de graduação presenciais para noventa por cento e da relação de alunos de graduação em cursos presenciais por professor para dezoito, ao final de cinco anos, a contar do início do plano. (BRASIL, 2007, $\S 1^{\circ}$, do Art. $1^{\circ}$ ).

O REUNI é um programa de reforma das IFES acoplado a um plus de financiamento para aquelas universidades que a ele aderirem. Esse conjunto de condicições é uma forma de estimular a concorrência entre as universidades federais. Talvez mais correto seria dizer que se trata de uma competição de regularidade e de busca de identidade ao modelo sugerido pelo MEC. De acordo com o Decreto 6.096/2007²,

$2 \mathrm{Na}$ Argentina, com o Programa de Reforma da Educação Superior (PRES), houve o que se convencionou chamar de "fondos concursables", em que as Universidades, com a finalidade de ampliar seu insuficiente orçamento próprio, concorriam em editais de financiamento publicados pelo Ministério da Educação. Para um maior detalhamento, ver Azevedo e Catani, 2004. 
O Ministério da Educação destinará ao Programa recursos financeiros, que serão reservados a cada universidade federal, na medida da elaboração e apresentação dos respectivos planos de reestruturação, a fim de suportar as despesas decorrentes das iniciativas propostas, especialmente no que respeita a:

I-Construção e readequação de infra-estrutura e equipamentos necessárias à realização dos objetivos do Programa;

II-Compra de bens e serviços necessários ao funcionamento dos novos regimes acadêmicos; e

III-Despesas de custeio e pessoal associadas à expansão das atividades decorrentes do plano de reestruturação (BRASIL, 2007, Art. $3^{\circ}$ ).

De forma semelhante ao conceito de contrato de gestão, instrumento inspirado nas propostas do MARE (Ministério da Administração Federal e da Reforma do Estado), da época do Ministro Bresser Pereira ${ }^{3}$, o REUNI condiciona o financiamento ao cumprimento de metas previamente acordadas. Segundo o referido decreto, "A proposta, se aprovada pelo Ministério da Educação, dará origem a instrumentos próprios, que fixarão os recursos financeiros adicionais destinados à universidade, vinculando os repasses ao cumprimentos de etapas" (Art. $6^{\circ}$ ).

Entretanto, demonstrando o predomínio da mão direita (finanças) sobre a mão esquerda (educação) ${ }^{4}$ do Estado, o REUNI está limitado à previsão orçamentária concedida, não havendo a garantia da efetividade, da continuidade e do cumprimento de desembolsos acordados. Assim, o Ministério da Educação subordina o REUNI e, conseqüentemente, o projeto de implantação da "Universidade Nova”, aos Ministérios do Planejamento e da Fazenda. Conforme o diploma legal, "O atendimento dos planos é condicionado à capacidade orçamentária e operacional do Ministério da Educação (Art. $3^{\circ}, \S^{\circ}$ )".

Porém, caso o Ministério da Educação e as universidades federais aderentes prosperarem no projeto de reestruturação, em termos esquemáticos a "Universidade Nova" seria uma proposta de uma nova arquitetura da organização curricular-programática dos cursos de graduação que ofereceria a possibilidade de formação básica por grandes áreas do conhecimento. Tomando-se por base o Documento Preliminar da UFBA, o Bacharelado Interdisciplinar seria com-

3 O Ministro Bresser Pereira tem organizada sua produção intelectual no sítio <http://www.bresserpereira. org.br>

4 Conforme metáfora presente no pequeno livro de combate de Pierre BOURDIEU, Contre-feux (1998). 
posto por dois conjuntos de componentes curriculares, o primeiro seria uma Formação Geral (FG) e o segundo de Formação Específica (FE) com vista a uma "orientação" profissional'. O Bacharelado Interdisciplinar

pode ser definido como curso de formação universitária interdisciplinar, "geral e propedêutica", devendo servir como requisito para: a) formação profissional de graduação; b) formação científica ou artística de pós-graduação. Terá duração de 6 semestres (ou ainda, 9 trimestres), com uma carga horária total mínima de 2.412 horas. A Carga Curricular do Bacharelado Interdisciplinar baseia-se no conceito de Blocos Curriculares, definidos como conjunto de módulos (cursos, disciplinas, atividades, programas, trabalhos orientados) cobertos pelos alunos durante o semestre ou quadrimestre letivo. Cada módulo equivale a quatro (4) horas/semana de atividade em sala de aula/ laboratório/ observatório. O BI compreende um mínimo de 24 e um máximo de 32 componentes curriculares [...]. " (UFBA, 2007, p. 9-10)

Figura 1 - Arquitetura curricular da Universidade Nova

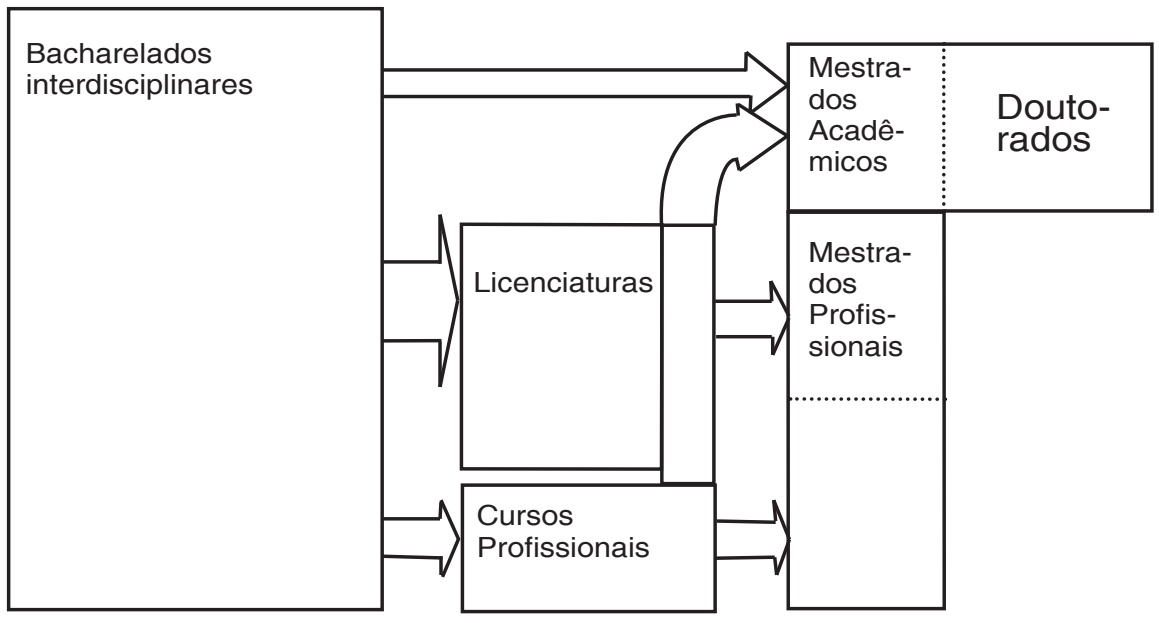

Fonte: UFBA, 2007, p. 9

5 "Após a conclusão da Formação Geral ao final do segundo ano, complementada com opções de blocos curriculares de Formação Específica, o aluno poderá requerer um Diploma de Curso Seqüencial. Caso lhe seja impossível prosseguir na trajetória de carreira profissional ou acadêmica, este título dar-lhe-á acesso a cursos superiores de Educação Profissional Tecnológica (+ 2 semestres), fazendo jus ao Diploma de Tecnólogo, conforme a legislação vigente" (UFBA, 2007, p. 13) 
Esse desenho curricular, próprio da concepção da Universidade Nova, está sendo analisado pelo Conselho de Ensino, Pesquisa e Extensão da UFBA que, a exemplo da Universidade de Brasília (UnB) e da Universidade Federal do $\mathrm{ABC}(\mathrm{UFABC})$, detém o pioneirismo nas discussões a respeito da implantação desse modelo. Conforme pode-se notar pela figura 1, o BI seria a base inicial da estrutura acadêmica (Primeiro Ciclo), teria duração três anos ${ }^{6}$ e se comporia da Formação Geral (FG) e Formação Específica (FE). A FG comportaria três modalidade de componentes curriculares: Eixos Básicos (EB), Eixos Interdisciplinares Básicos (ET) e Eixo Integrados (EI). Dispensando-se de maiores discussões sobre as especificidades dos componentes curriculares, segundo o Documento Preliminar apresentado pela UFBA, três Bacharelados Interdisciplinares seriam possíveis: $\mathrm{BI}$ em Artes $(\mathrm{BA})^{7}$, BI em Humanidades $(\mathrm{BH})^{8}$ e BI em Ciências (BC) $)^{9}$ (UFBA, 2007, p. 13). Essa arquitetura coincide parcialmente com o modelo norte-americano e com o do Processo de Bolonha. Segundo Márcia Pontes, Coordenadora de Ensino de Graduação na UFBA,

O modelo europeu proposto pelo Processo de Bolonha é outro que pode servir para enriquecer os debates brasileiros sobre a Universidade Nova [...] Com esse projeto, possivelmente as instituições européias aumentarão sua competitividade e formarão melhor os egressos, com um currículo mais adaptado às exigências do mercado de trabalho. Além disso, estudantes e professores terão maior mobilidade entre as várias instituições do continente [...] (PONTES, M. apud BORGES, 2007).

Efetivamente, os formuladores da Universidade Nova são reticentes em admitir coincidências com os modelos existentes nos EUA ou na Europa. Naomar de Almeida Filho, reitor da UFBA e principal sistematizador da idéia, intitula um dos principais capítulos de seu livro, Universidade Nova: textos críticos e esperançosos, de "Universidade Nova: Nem Harvard Nem Bolonha" (ALMEIDA FILHO, 2007a, p. 259). Entretanto, em essência, a Universidade Nova não é uma negação dos modelos existentes nos EUA ou em implantação na Europa (Processo de Bolonha), mas sim, uma mescla tímida de ambos. Há algo contraditório no discurso a favor da Universidade Nova. Por um lado, no

6 Com a possibilidade de obtenção de um Diploma de Curso Seqüencial ao final de dois anos (UFBA, 2007, p. 13).

7 Áreas de Concentração do BA: Artes Visuais, Dança, Teatro, Música e Cinema e Vídeo.

8 Áreas de Concentração do BH: Letras, Filosofia, Educação, Comunicação, Ciências Humanas e Ciências Sociais Aplicadas.

9 Áreas de Concentração do BC: Ciências Exatas, Ciências da Matéria, Ciências da Vida, Ciências da Saúde e Ciências de Informação. 
título, Almeida Filho nega os modelos norte-americano (Harvard) e europeu (Bolonha); por outro, declara que "é imprescindível que, nas relações complexas de trocas internacionais, tenhamos sistemas educacionais que sejam valorizados e compatíveis (sem grifos no original) com os centros intelectuais e econômicos do mundo contemporâneo [EUA e Europa?]" (2007a, p. 293).

Almeida Filho também afirma que a Reforma Universitária de 1968, inspirada no modelo norte-americano, foi deturpada pelo tradicionalismo na universidade brasileira. Mais que uma crítica ao modelo de 1968, o reitor da UFBA lamenta a respeito da incompletude da Reforma inspirada no Relatório Atcon ${ }^{10}$. Segundo suas próprias palavras, "em menos de 10 anos, as universidades brasileiras que passaram por aquela reforma já haviam recuado, quase completamente, em relação às alterações de estrutura institucional e de arquitetura curricular" (2007a, p. 293).

A lógica da Universidade Nova pode ser compreendida como um modo de se afastar do Processo Bolonha e se reaproximar do modelo norte-americano (não totalmente implantado em 1968), isto sem precisar montar a infra-estrutura necessária da universidade norte-americana e sem a necessidade de encaminhar a formação profissional na graduação como, de fato, continua acontecendo na Europa do Processo de Bolonha.

Como tem acontecido na história recente (séculos XX e XXI) da diplomacia brasileira, ao que tudo indica, o Brasil aprecia e admira as novidades européias, embora deixe-se levar pela força gravitacional dos EUA. Apesar do discurso otimista, o Brasil, com a Universidade Nova, corre o risco de transformar suas Universidades Públicas em Liberal Arts Colleges, abrindo mão de alcançar o padrão de qualidade das universidades de primeira linha dos EUA(Universidade de Harvard?). Almeida Filho (2007b), antecipando-se à crítica, escreve que

Nos Estados Unidos, a educação fundamental e média, desde o início do século XX, é gratuita e universalizada. A elite brasileira critica a high-school americana por ser mais fraca que o nosso padrão do ensino médio. Este é um equívoco, pois se compara um sistema público de educação (o norte-americano) com uma elite de escolas privadas, especialistas em preparar jovens para ingresso em universidades públicas (brasileiras). $\mathrm{O}$ aluno norte-americano entra na universidade para um período de formação científica e cultural no undergraduate college, e só depois tem acesso a cursos de mestrado ou doutorado, definidores de profissões.

10 Original reflexão a respeito da reforma universitária de 1968 pode ser encontrada em Cunha (1988, Luiz Antônio. A Universidade Reformanda (1988) - há nova edição, lançada em 2007, pela Editora UNESP. 
Não é supérfluo lembrar uma máxima inglesa, "Os EUA, com 4.000 instituições de educação superior, provavelmente tem cinqüenta das melhores universidades do Mundo e, sem dúvida, tem as 500 piores" (STEVENS, 2004, p. xiii) ${ }^{11}$. Em suma, há nos EUA uma grande amplitude de qualidade. Em qual grupo as Universidades brasileiras estariam participando, entre as melhores ou as piores? Seriam os Bacharelados Interdisciplinares (BI) uma capitulação à insuficiência formativa do Ensino Médio público brasileiro e, efetivamente, funcionando como cursos pós-médios?

Além disso, de modo ousado, Almeida Filho manifesta que a universidade brasileira deixou de ser o locus de formação profissional e de quadros de direção e que este papel (ensino - formação) está sendo cumprido por organizações que desconhecem as missões precípuas de toda Universidade (ensino, pesquisa e extensão):

nem mesmo o deus ex-machina chamado 'mercado de trabalho' parece mais se importar com os padrões de formação profissional dos egressos da educação universitária. Grandes corporações, empresas de pequeno e médio porte, instituições públicas (principalmente do judiciário), simplesmente retreinam todos os profissionais recrutados para compor seus quadros técnicos e executivos, como se a passagem pela instituição educacional e a conquista do diploma universitário apenas cumprissem a função de credenciamento e não de formação profissional (2007, p. 294).

As empresas, e mesmo o poder público, há muitos anos têm políticas de educação e de treinamento de pessoal. Não pode haver confusão entre o pragmatismo do empregador e a formação do cidadão. Além disso, não se pode abster do debate alegando que está se defendendo a "liberdade de escolha" na educação, conforme declara Manuel Palácios, então dirigente da Sesu/MEC: "a grande razão de ser da Universidade Nova é a ampliação da liberdade no ensino superior. Isso diz respeito a muitas esferas, e tem reflexo especial para os alunos, que terão maior possibilidade de escolha para definir suas trajetórias acadêmicas" (CASTRO, 2007).

Historicamente, as forças progressistas da sociedade defendem que a escola (e a universidade) ofereça formação não interesseira ao cidadão, pois as instituições públicas não podem, simplesmente, sucumbir ao imediatismo de mercado. Porém, diante das carências existentes nos países periféricos, não se

11 "the US, with 4.000 institutions of higher education, probably has fifty of the best universities in the world and undoubtedly has 500 of the worst" (STEVENS, 2004, p. xiii). 
pode abrir mão de um projeto soberano e sustentável. Diante dessa realidade, estaria uma fração da elite dirigente, após o Brasil experimentar baixos níveis de crescimento nos últimos 20 anos, conformando-se à estagnação e abdicando da oferta massiva e sustentada de profissionais e quadros para o desenvolvimento do País? Qual o "novo" caminho para o Brasil? Sem Harvard e sem Bolonha e descartando os Liberal Arts Colleges, resta a ousadia de construir um espaço de educação superior no Hemisfério Sul que seja compatível com os centros científicos mundiais, que possua reconhecida qualidade, que promova a inclusão social, que considere a educação com um bem público, que permita a mobilidade acadêmica de professores e discentes e que a internacionalização da educação superior tenha a marca da solidariedade.

Para sustentar a idéia da "Universidade Nova", Almeida Filho recorre ao legendário educador Anísio Teixeira que, com espírito republicano, entendia que "educação não é privilégio" (2007a). Procurando defender um projeto de desenvolvimento do Brasil, Teixeira fez constantes referências ao modelo humboldtiano de universidade, que se caracteriza pela aliança entre o ensino e a pesquisa. Para ele, a universidade brasileira deveria ser transformadora da cultura nacional. Do mesmo modo que o modelo da Universidade de Berlin (fundada por Humboldt em 1810) auxiliou a superação da letargia alemã, o educador baiano considerava que uma nova universidade no Brasil poderia cumprir o mesmo papel. Em suas palavras,

O processo iniciado por Humboldt na Universidade de Berlin generalizou-se por toda a Europa. Antes desse período, toda a universidade estava a transmitir um conhecimento universal já existente e já formulado pelos livros antigos. Com Humboldt, surge para a universidade a função de se elaborar a cultura nacional que vai ser ensinada [...]. Então, não se trata de dizer apenas que a universidade precisa dedicar-se à pesquisa. Ela tem de reformular o conhecimento que iria ensinar [...]. A universidade somente será de pesquisa quando passar a reformular a cultura que vai ensinar (TEIXEIRA, 2005, p. 190).

Se se deseja realmente uma sociedade humanizada, solidária e desenvolvida, não se pode conformar com a sociedade realmente existente. A universidade é o lugar da insatisfação e da crítica constante. A simples mudança da arquitetura curricular da universidade não a torna uma universidade nova. A universidade brasileira para se renovar precisa tomar a lição histórica de Humboldt, o que não se traduz por germanizar-se, norte-americanizar-se ou europeizar-se. A universidade humboldtiana não está esgotada no Brasil, não se podendo abortar 
um projeto de universidade que ainda está em gestação e, mesmo assim, tem gerado ciência e massa crítica para o País. No campo da pesquisa, segundo a CAPES,

O Brasil conquistou em 2006 a 15ª posição no ranking dos países com maior produção de novos conhecimentos científicos do mundo, subindo duas colocações comparado a 2005 [...]. Os dados internacionais (Capes/ Thomson NSI 2006) mostram que os pesquisadores brasileiros publicaram nesse ano 16.872 artigos nas mais importantes revistas científicas do mundo, apenas cerca de quatro vezes menos que a Alemanha, a segunda do ranking, que publica $8,1 \%$ do total mundial. Já em relação a 2004, o crescimento foi de $33 \%$, três vezes a média mundial. O Brasil ultrapassou a Suécia e Suíça [...]. No topo do ranking estão os Estados Unidos, que são responsáveis por 32,3\% da produção científica mundial; em seguida vem a Alemanha, que desloca o Japão e assume a segunda posição com 8,1\%; a China assume o quarto lugar e, em quinto, está a Inglaterra. (CUNHA, 2007).

As melhores universidades brasileiras, como a USP, Unicamp, UFRJ, UNESP, UFRGS e UFMG, conquistaram essa posição pela inspiração humboldtiana de aliar ensino, pesquisa e extensão. Não se trata de preservar possíveis vícios existentes (traços de corporativismo, elitismo ou oligarquismo), mas de fazer avançar, propagar e massificar a cultura e a ciência elaboradas nas universidades ${ }^{12}$. Conforme o próprio Anísio Teixeira (2005, p. 191),

É absolutamente necessário que a educação seja um processo de incorporação pelo aluno da cultura real da sociedade, cultura de que a universidade seria a reformadora; e não um acréscimo, não um ornamento, não um simples processo informativo. Só conseguiremos transmitir a cultura e o saber quando transformarmos as nossas instituições educacionais em instituições realmente embebidas no solo brasileiro, na terra brasileira, a refletirem a peculiaridade brasileira e o modo de pensar brasileiro. Foi exatamente isso que Humboldt imaginou para a Alemanha.

12 Dentre as 15 universidades com maior produção científica no momento, 11 cresceram mais de $200 \%$ no período 1996-2006, segundo os dados mais recentes da Coordenação de Aperfeiçoamento de Pessoal de Nível Superior (Capes), obtidos com exclusividade pelo jornal O Estado de S. Paulo. As seis primeiras colocadas - USP, Unicamp, UFRJ, Unesp, UFRGS e UFMG - mantêm suas posições no ranking desde 1996, com aumento significativo no número de trabalhos publicados. A Universidade Federal de Minas Gerais é a de maior destaque no grupo, com aumento de $258 \%$. A Universidade de São Paulo também triplicou sua produção no período (aumento de $200 \%$ ), sustentando posição isolada como maior instituição produtora de conhecimento do país. Duas universidades menores deram saltos espantosos: a Universidade Federal de Viçosa (UFV) aumentou sua produção científica em 640\%, enquanto a Universidade Federal do Ceará (UFC) atingiu $410 \%$ (ESCOBAR). 
Além disso, apesar da construção dicotômica de Naomar, como que fazendo oposição entre o modelo norte-americano e o europeu, a universidade nos EUA é o resultado das relações entre e o novo e o velho mundos, entre o projeto de independência nacional e a herança intelectual metropolitana, entre o senso prático e a pesquisa básica. A Universidade de Berlin tornou-se referência na consolidação do sistema universitário norte-americano, servindo como amálgama de marca original para a construção da independência acadêmica. Perkin classifica a história da universidade norte-americana em três fases, sendo que a terceira e última recebe fortemente a influência humboldtiana. De acordo com Perkin $(2006, \text { p. 184) })^{13}$,

Depois da Revolução Americana [independência], as instituições fundadas pelos colonizadores passaram por três fases de desenvolvimento. Primeiramente, ocorreu a promoção das universidades estaduais, começando com as Universidades do Norte da Carolina e da Geórgia, respectivamente, abertas em 1795 e 1801. Eram instituições seculares que contavam com o forte esteio do financiamento público, mas também submetidas ao monitoramento da Assembléia Legislativa do Estado. A segunda fase é marcada pela criação, de acordo com a Lei Morril (Morril Act) de 1862, de land-grant colleges; entre essas instituições pioneiras de educação superior está o Ezra Cornell's College (1869), localizado na cidade de Ithaca, Estado de Nova York, no qual 'qualquer pessoa pode encontrar instruções em qualquer área de estudos', particularmente nas ciências aplicadas com vistas a servir à recente sociedade em processo de industrialização em setores como a agricultura e a engenharia. A educação norteamericana teve um olhar tanto para o lado prático como para o lado intelectual e moral, mas o grande salto a frente aconteceu na terceira fase de desenvolvimento, com a influência do modelo alemão de universidade de pesquisa, começando com John Hopkins em 1876 e logo imitado por Harvard, Yale, Columbia, Northwestern, Michigan e outras universidades, públicas e privadas, estendendo-se a Stanford e Berkeley na Costa Oeste. A universidade de pesquisa norte-americana ainda guarda alguma semelhança com o modelo alemão.

13 After the American Revolution three overlapping developments built on the foundations laid by the colonists. First was the rise of the state university, beginning with the Universities of North Carolina and Georgia, opened in 1795 and 1801, secular institutions with all the strength public funding behind them but also under the monitoringeye of the state legislature. Second was the creation, under the Morril Act the 1862, of the land-grant colleges, among the earliest being Ezra Cornell's college at Ithaca in upper New York (1869), where 'any person can find instruction in any study', particularly in those applied sciences so useful to a newly industrializing society as agriculture and engineering. American education had an eye for the practical as well as the intellectual and moral, but the great leap forward resulted from the third development, the important of the German model of the research university, beginning with John Hopkins in 1876 and soon to be imitated by Harvard, Yale, Columbia, Northwestern, Michigan, and others universities, state and private, all the way across to Stanford and Berkeley on the West Coast. Yet the American research university bore little resemblance to the German model (PERKIN, 2006, p. 184). 
Percebe-se que o projeto de país, independente e soberano, impulsionou o modelo norte-americano de universidade, preparado para a pesquisa e para responder às demandas da sociedade. $\mathrm{O}$ Brasil, ao discutir a reforma universitária, precisa discutir ao mesmo tempo seu projeto de país. O projeto brasileiro de universidade pública, gratuita, de qualidade e com pertinência social necessita, de modo urgente, ser encaminhado com a refundação do projeto de país, pois, conforme Boaventura de Souza Santos (2004, p. 47-49),

Efectivamente, nos últimos vinte anos, a globalização neoliberal lançou um ataque devastador à idéia de projecto nacional [...]. No caso da universidade pública, os efeitos deste ataque não se limitaram à crise financeira. Repercutiram-se directa ou indirectamente na definição de prioridades de pesquisa e de formação [...]. As universidades globais dos EUA, da Austrália e da Nova Zelândia, actuam no quadro de projectos nacionais que têm o mundo como espaço de acção [...]. Para os países periféricos e semiperiféricos o novo contexto global exige uma total reinvenção do projecto nacional sem a qual não haverá reinvenção da universidade.

Por fim, talvez não seja deslocada a lembrança de uma passagem do livro produzido por um coletivo de professores franceses, liderado por Pierre Bourdieu, que vem a se constituir em verdadeiro antídoto contra o pragmatismo desenfreado que, em geral, dá o tom em muitos pontos do debate atual envolvendo reformas e reformadores:

Em oposição às carreiras fechadas que exigem e impõem uma adaptação precoce à ordem social tal como ela é, a universidade é um lugar, talvez o único, de confrontação crítica entre as gerações, um lugar de experiências múltiplas, efetivas, políticas, artísticas, certamente insubstituíveis, uma oportunidade única para muitos rapazes e moças de viver, por um tempo mais ou menos longo, qualquer coisa que se assemelha a uma vida intelectual, antes de entrar de uma vez por todas na ordem social [...]. Com a derrocada desse lugar de concorrência e de questionamento dos saberes que o ensino superior ainda representa, é uma forma insubstituível do espírito crítico e cívico, do espírito cívico crítico, que viria a desaparecer, atrofiando toda reflexão geral, capaz de ultrapassar os limites das especializações disciplinares e das competências economicamente funcionais, e assegurando para toda uma parcela da juventude esta espécie de distância crítica com relação ao seu destino social que é a condição de uma vida cultural esclarecida e de uma participação ativa na democracia. (ARESER, 1997, p. 120-121). 


\section{Referências}

ALMEIDA FILHO, Naomar. Universidade nova: textos críticos e esperançosos. Brasília: UnB; Salvador: EDUFBA, 2007a.

. Universidade nova: nem Harvard, nem Bolonha. Disponível em: $<$ http://www.twiki.ufba.br/twiki/bin/view/UniversidadeNova/Artigo_n1> Acesso em: 21 ago. 2007b.

AMARAL, A.; MAGALHÃES, A.. O conceito de stakeholder e o novo paradigma do ensino superior. Revista Portuguesa de Educação, Braga, Portugal, v. 13, n. 2, p. 7-28, 2000.

ANTUNES, F. Governação e espaço europeu de educação: regulação da educação e visões para o projecto "Europa". Revista Crítica de Ciências Sociais, Coimbra, Portugal, n. 75, p. 63-93, 2006 a.

ANTUNES, F. Globalisation and europeification of education policies: routes, processes and metamorphoses. European Educational Research Journal, United Kingdom v. 5, n. 1, p. 38-56, 2006b. Disponível em: <http: www. wwwords.eu.EERJ>

ARESER (Association de réflexion sur les enseignements supérieures et la recherche). Quelques Diagnostiques et Remèdes Urgents pour une Université en Péril. Paris: Raisons D`Agir Éditions, 1997.

AZEVEDO, M.L.N. A integração dos sistemas de educação superior na Europa. De Roma a Bolonha ou da integração económica à integração académica. In: SILVA JR., J. dos R.; OLIVEIRA, J. F.; MANCEBO, D. (Orgs.). Reforma universitária. dimensões e perspectivas. Campinas, SP: Alínea, 2006. p. 171186

AZEVEDO, M. L. N.; CATANI, A.M. Universidade e Neoliberalismo: o Banco Mundial e a Reforma Univesitária na Argentina (1989-1999). Londrina, PR: Práxis, 2004.

BARROSO, J. O estado e a educação. A regulação transnacional, a regulação nacional e a regulação local. In: BARROSO, J. (Org.). A regulação das políticas públicas de educação. Lisboa: Educa, 2006. p. 43-70

BORGES, Rodolfo. Inspiração na Europa e nos EUA. Brasília: UnB-Secon, 30 mar. 2007. Disponível em: < http://www.secom.unb.br/unbagencia/ag030791.htm>. Acesso em: 05 abr. 2007 
BOURDIEU, Pierre. Contre-feux: propos pour servir à la résistance contre 1'ìnvasion néo-libérale. Paris: Éditions Liber-Raisons d'Agir, 1998.

BRASIL. Decreto n 6.096, 24 abr. 2007. Institui o Programa de Apoio a Planos de Reestruturação e Expansão das Universidades Federais - REUNI. Diário Oficial da União, Brasília, 25. abr. 2007.

Casa Civil da Presidência da República. Exposição de Motivos. Projeto de Lei da reforma da educação superior. Brasília: PL n. 7200/2007, MEC/ MF/MT/MCT. 12 jun. 2006.

. MINISTÉRIO DA EDUCAÇÃO. Reafirmando princípios e consolidando diretrizes da reforma da educação superior. Documento II. Brasília: 02 ago. 2004. Disponível em: <http://www.mec.gov.br> Acesso em: 15 mar. 2005.

Comunicado de Bergen. The European Higher Education Area. Achieving the Goals. Disponível em: http://www.mctes.pt/docs/ficheiros/Bergen_Comunicado.pdf, 2005 Acesso em: 28 jun. 2007.

COMUNICADO de Berlim. Realising The European Higher Education Area. Disponível em: <http://www.mctes.pt/docs/ficheiros/Comunicado_de_Berlim. pdf.2003> Acesso em: 28 jun. 2007.

COMUNICADO de Londres. Towards The European Higher Education Area: responding to challenges in a globalised world. <http://www.mctes. pt/docs/ficheiros/Londres_Communique_18May07.pdf, 2007>. Acesso em: 28 jun. 2007.

COMUNICADO de Praga. Towards The European Higher Education Area. Disponível em: <http://www.mctes.pt/ficheiros/Comunicado_de_Praga.pdf ,2001>. Acesso em: 28 jun. 2007.

CASTRO, André Augusto. MEC apóia Universidade Nova. Disponível em: $<$ http://www.secom.unb.br/unbagencia/ag0307-90.htm>. Acesso em: 05 abr. 2007.

CROZIER, F.; CURVALE, B.; HÉNARD, F. Final Report on The Quality Convergence II Project: promoting epistemological approaches to quality assurance. In: CROZIER, F. et al., Terminology of quality assurance: towards shared European values? Helsínquia: European Association for Quality Assurance in Higher Education, p. 22-28, 2006. Disponível em: <http://www.enqa. eu/files/terminology_v01.pdf>. Acesso em: 28 jun. 2007. 
CUNHA, Luiz Antônio. A universidade reformanda. Rio de Janeiro: Francisco Alves, 1988.

CUNHA, Adriane. Brasil sobe duas posições no ranking da produção científica. Disponível em: <http://www.capes.gov.br/servicos/salaimprensa/ noticias/noticia_0709.html>. Acesso em: 10 jul. 2007.

DECLARAÇÃO de Bolonha. Disponível em: < http://www.mctes.pt/docs/ficheiros/Declaracao_de_Bolonha.pdf 1999>. Acesso em: 28 jun. 2007.

DECLARAÇÃO de Sorbonne. Disponível em: <http://www.mctes.pt/docs/ficheiros/Declaracao_da_Sorbonne.pdf 1998>. Acesso em: 28 jun. 2007.

DIAS SOBRINHO, J. Dilemas da educação superior no mundo globalizado: sociedade do conhecimento ou economia do conhecimento? São Paulo: Casa do Psicólogo, 2005.

ENQA. (Standards and Guidelines for Quality Assurance in the European Higher Education Area. Helsínquia: European Association for Quality Assurance in Higher Education. Disponível em: <http://www.enqa.eu/files/BergenReport210205.pdf, 2005>. Acesso em: 28 jun. 2007.

. Quality Assurance of Higher Education in Portugal. Helsínquia: European Association for Quality Assurance in Higher Education. Disponível em: <http://www.enqa.eu/pubs.lasso 2006>. Acesso em: 28 jun. 2007.

ESCOBAR, Hector. Disponível em: <http://www.bu.ufsc.br/cbbu>. Acesso em: 01 ago. 2007.

ESIB. Bologna With Student Eyes. Edition. Londres: The National Unions of Students in Europe. Disponível em: <http://www.mctes.pt/docs/ficheiros/ ESIB_Bologna_With_Student_Eyes_full.pdf $>$. Acesso em: 28 jun. 2007.

FIGARI, G.; TOURMEN, C. La référentialisation: une façon de modéliser l'évaluation de programme, entre théorie et pratique. Mesure et Évaluation en Éducation, Canadá, v. 29, n. 3, p. 5-25, 2006.

LIMA, L. C. O paradigma da educação contábil. Políticas educativas e perspectivas gerencialistas no ensino superior em Portugal. Revista Brasileira de Educação, Rio de Janeiro, n. 4, p. 43-59, 1997.

. Educação ao longo da vida. Entre a mão direita e a mão esquerda de Miró. São Paulo: Cortez, 2007 
MAGALHÃES, A. A identidade do ensino superior. Política, conhecimento e educação numa época de transição. Lisboa: Fundação Calouste Gulbenkian; Fundação para a Ciência e a Tecnologia, 2004.

OCDE. Reviews of National Policies for Education. Tertiary Education in Portugal. Disponível em: <http://www.mctes.pt/docs/ficheiros/OCDE_124_paginas_pdf, 2006>. Acesso em: 28 jun. 2007.

PERKIN, Harold. History of universities. In: FOREST, James J.F.; ALTBACH, Philip G. (Orgs.). International handbook of higher education. Dordrecht (Netherlands): Springer, 2006. p. 159-205.

PORTUGAL. Conselho Nacional de Educação. Parecer sobre a Implementação do Processo de Bolonha (Parecer n. ${ }^{\circ}$ 6/2004), <http://www.cnedu.pt/files/1176995568_Parecer_2.2004.pdf2004>. Acesso em: 28 jun. 2007.

. Regime Jurídico dos Graus e Diplomas do Ensino Superior. Decreto-lei n. 74/2006, de 24 de Março. Disponível em: < http://www.mctes.pt/docs/ ficheiros/Decreto_lei_no_74_2006.pdf>. 2007. Acesso em 28 jun. 2007.

. Regime Jurídico das Instituições de Ensino Superior. Disponível em: <http://www.mctes.pt/docs/ficheiros/RJIES.pdf>. Acesso em: 28 jun. $2007 a$.

PORTUGAL.. Agência de Avaliação e Acreditação para a Garantia da Qualidade do Ensino Superior. Projecto de Decreto-lei para Consulta Pública. Disponível em: <http://www.mctes.pt/docs/ficheiros/projecto_cp.pdf $>$.Acesso em: 28 jun. $2007 \mathrm{~b}$.

ROSANVALLON, P. La contre-démocratie. La politique à l'âge de la défiance. Paris: Seuil, 2006.

SANTIAGO, R.; MAGALHÃES, A.; CARVALHO, T. O Surgimento do managerialismo no sistema de ensino superior português. Lisboa: Fundação das Universidades Portuguesas, 2005.

SANTOS, B. S. A universidade no século XXI: para uma reforma democrática e emancipatória da universidade. Educação, Sociedade \& Culturas, Porto, Portugal, n. 23, p. 137-202, 2005.

A universidade no século XXI: para uma reforma democrática e emancipatória da universidade. São Paulo: Cortez, 2004

SEIXAS, A. M. Políticas educativas e ensino superior em Portugal. Coimbra: Quarteto, 2003. 
SIMÃO, J. V.; SANTOS, S. M. dos; COSTA, A. Ambição para a Excelência. A Oportunidade de Bolonha. Lisboa: Gradiva, 2005.

STEVENS, Robert. University to Uni. The politics of higher education in England since 1944. London: Politico's Publishing, 2004.

TEIXEIRA, Anísio. Educação não é privilégio. Rio de Janeiro: Editora UFRJ, 2007.

. Ensino Superior no Brasil. Rio de Janeiro: Editora UFRJ, 2005.

UFBA. Universidade Nova: Plano de Expansão e Reestruturação da Arquitetura Curricular na Universidade Federal da Bahia. Documento Preliminar. Campinas, Mimeo, 2007. 